\title{
ОСНОВНЫЕ ПРИНЦИПЫ РАЗВИТИЯ ЛОГИСТИЧЕСКОЙ ИНФРАСТРУКТУРЫ В АБАКАНО-МИНУСИНСКОЙ ГОРОДСКОЙ АГЛОМЕРАЦИИ
}

\section{P.G.Shvalov}

\section{THE MAIN PRINCIPLES OF LOGISTIC INFRASTRUCTURE DEVELOPMENT IN ABAKAN-MINUSINSK URBAN AGRLOMERATION}

Оптимизация регионального развития является одной из ключевых задач, стоящих перед Российской Федерацией в силу роста конкуренции на ключевых рынках и того факта, что добыча и первичная переработка задействованных ресурсов в стране носит децентрализованный характер. Наибольшую актуальность это приобретает в регионах азиатской части страны, обеспечивающих большую часть извлекаемых полезных ископаемьх. Вследствие того что логистическая инфраструктура в данньх регионах развивалась по принципу минимальной достаточности, в настоящее время уровень ее развития уступает показателям развитых стран, препятствуя расширению спектра логистических услуг, в том числе и повышению качества транспортного обслуживания. Как следствие, доля транспортных и складских издержек в себестоимости продукции как первичного, так и вторичного сектора Российской Федерации является недопустимо высокой, что снижает конкурентоспособность региональной экономики в целом. Более того, недостаточный уровень развития логистической инфраструктуры негативным образом сказывается на качестве жизни в регионах Сибирского и Дальневосточного федеральных округов, что, наряду с неблагоприятными условиями окружающей среды, влечет за собой отток населения в более развитые регионы страны, тем самым снижая совокупный спрос на производимую в регионах продукцию и еще более увеличивая себестоимость продукции по причине необходимости организации работ вахтовым методом. Актуальность развития логистической инфраструктуры проявляется на региональном уровне даже в большей степени, чем по стране в целом, так как она выступает в качестве интегратора элементов институциональной, экономической и социальной инфраструктуры. Был проведен анализ Абакано-Минусинской городской агломерации, образованной на территории Красноярского края и Республики Хакасии, доказана ее сущность в качестве конурбации. Рассматривается существующая 
логистическая инфраструктура территории, выделяются ее основные недостатки и определяются ключевые направления развития.

Ключевъе слова: логистика, региональная логистика, логистическая инфраструктура, социально-экономического развитие, Красноярский край, Республика Хакасия, городская агломеращия, логистические центры.

The optimization of regional development is one of the key tasks facing the Russian Federation owing to the growth of the competition on the key markets and that fact that production and primary processing of involved resources in the country has a decentralized character. It gains the greatest relevance in the regions of Asian part of the country providing the most part of extracted minerals. As the logistic infrastructure in these regions is developed by the principle of the minimum sufficiency, now the level of its development concedes to the indicators of developed countries, interfering with the expansion of a range of logistic services, including the improvement of the quality of transport service. As a result the share of transport and warehouse costs in cost of products of both primary, and secondary sector of the Russian Federation is inadmissibly high that reduces competitiveness of regional economy in general. Moreover, insufficient level of the development of logistic infrastructure negatively affects the quality of life in the regions of Siberian and Far East federal districts that, along with adverse conditions of the environment, involves the outflow of the population to more developed regions of the country, thereby reducing cumulative demand for the production made in the regions and even more increasing product cost because of the need of the organization of works by a shift method. As a result, the relevance of the development of logistic infrastructure is shown at regional level even more than over the country in general as it acts as the integrator of the elements of institutional, economic and social infrastructure. The analysis of Abakan-Minusinsk city agglomeration formed on the territory of Krasnoyarsk Region and the Republic of Khakassia has been carried out, its essence as a conurbation is proved. The existing logistic infrastructure of the territory has been considered, its main shortcomings have been allocated and the key directions of development have been defined.

Keywords: logistics, regional logistics, logistics infrastructure, social and economic development, Krasnoyarsk Region, the Republic of Khakassia, urban agglomeration, logistics centers.

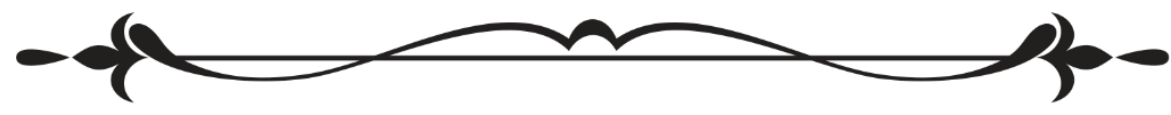




\section{Социально-экономический и әуманитарный журнал Красноярского ГАУ. 2020. №1}

Необходимость реализации концепции пространственного развития Российской Федерации приобретает все большую актуальность в наши дни. Низкая плотность населения, большое расстояние между объектами экономической инфраструктуры диктуют потребность в системном, комплексном развитии территорий. С учетом недостаточной обеспеченности природными ресурсами регионов европейской части страны особую актуальность приобретает территориальное развитие регионов Сибирского федерального округа.

Следствием большой территориальной разбросанности объектов экономической инфраструктуры является повышенный уровень транспортных издержек, а также следующий из него повышенный уровень складских издержек, вызванный неоптимальным объемом сырья и готовой продукции, поставляемой в пункты потребления. Отсюда следует, что логистическая инфраструктура, являясь одной из важнейших системных составляющих современного хозяйства, обеспечивая движение материальных, людских, информационных, финансовых и сервисных потоков, приобретает особое значение при определении направлений территориального развития. Поскольку все три инфраструктуры: экономическая, социальная, институциональная, - оказываются тесно взаимосвязанными, встает вопрос об инфраструктурной поддержке их совместного функционирования с целью максимизации отдачи от их деятельности и получения синергетического эффекта. Данную роль принимает логистическая инфраструктура, которая подразделяется в этом случае на подсистемы: логистическую инфраструктуру объектов социальной сферы, логистическую инфраструктуру объектов экономической сферы и логистическую инфраструктуру объектов институциональной сферы $[1,2]$.

Следует принимать во внимание, что с конца XX века основную роль в логистике играет интегральная парадигма, в которой в настоящее время приобретает актуальность концепция управления цепями поставок (SCM), базирующаяся на консолидации участников товаропроводящей системы в целях ее бесперебойного и непрерывного функционирования [3, 4]. Под SCM понимается системный подход к интегрированному планированию и управлению всем потоком информации, материалов и услуг от поставщиков сырья через предприятия и склады до конечного потребителя [5].

При формировании интегрированной логистической инфраструктуры возникает необходимость внесения существенных изменений в процесс функционирования элементов региональной логистической инфраструктуры в направлении интеграции объектов социальной, экономической и институциональной инфраструктур в целях поддержки возникающего синергетического эффекта. Возникновение синергии в 
территориальных логистических системах связывается с влиянием следующих эффектов:

- операционной экономии (операционной синергии) [6, 7];

- агломерации [6];

- повышения эффективности работы в цепях и сетях поставок [7];

- более четкого следования целям социально-экономического развития территории [8];

- объединения управленческих способностей команды, или командной синергии [8].

Интеграция инфраструктур на региональном уровне создает условия для формирования городских агломераций, под которыми понимаются компактные объединения населенных пунктов и близлежащих территорий в единую логистическую систему, обладающую общностью ключевых инфраструктурных объектов, потоки между которыми функционируют системно. Важно отметить, что образование городских агломераций не предусматривает административного объединения территорий: естественный процесс агломерационного развития позволяет сформировать их на межрегиональном и даже межгосударственном уровне.

В качестве примера рассмотрим Абакано-Минусинскую городскую агломерацию, сложившуюся естественным путем на юге Красноярского края и Республики Хакасии (рис. 1). Ядром данной агломерации выступает г. Абакан, концентрирующий в себе 48,28 \% от численности населения. Тем не менее, учитывая особенности размещения объектов институциональной инфраструктуры вследствие расположения в рамках двух регионов Российской Федерации, данную агломерацию можно рассматривать в качестве конурбации.

Следует отметить, что часть населенных пунктов, входящих в состав Минусинского, Алтайского и Усть-Абаканского районов, не были включены в состав агломерации по причине несоответствия признаку общности объектов логистической инфраструктуры. К примеру, ряд населенных пунктов, пространственно отдаленных от ядра городской агломерации на небольшое расстояние, не имеют достаточной интеграции по причине отсутствия должной дорожно-транспортной инфраструктуры. В результате, в состав агломерации можно включить административно-территориальные образования, представленные в таблице 1, обладающие общностью объектов экономической, социальной, институциональной и логистической инфраструктуры.

Согласно методике, разработанной в [9], построим граф АбаканоМинусинской городской агломерации (рис. 2), где вершины графа соответствуют номерам административно-территориальных образований из таблицы 1. 


\section{Социалъно-экономический и гуманитарный журнал Красноярского ГАУ. 2о2о. Nㅡ믄}

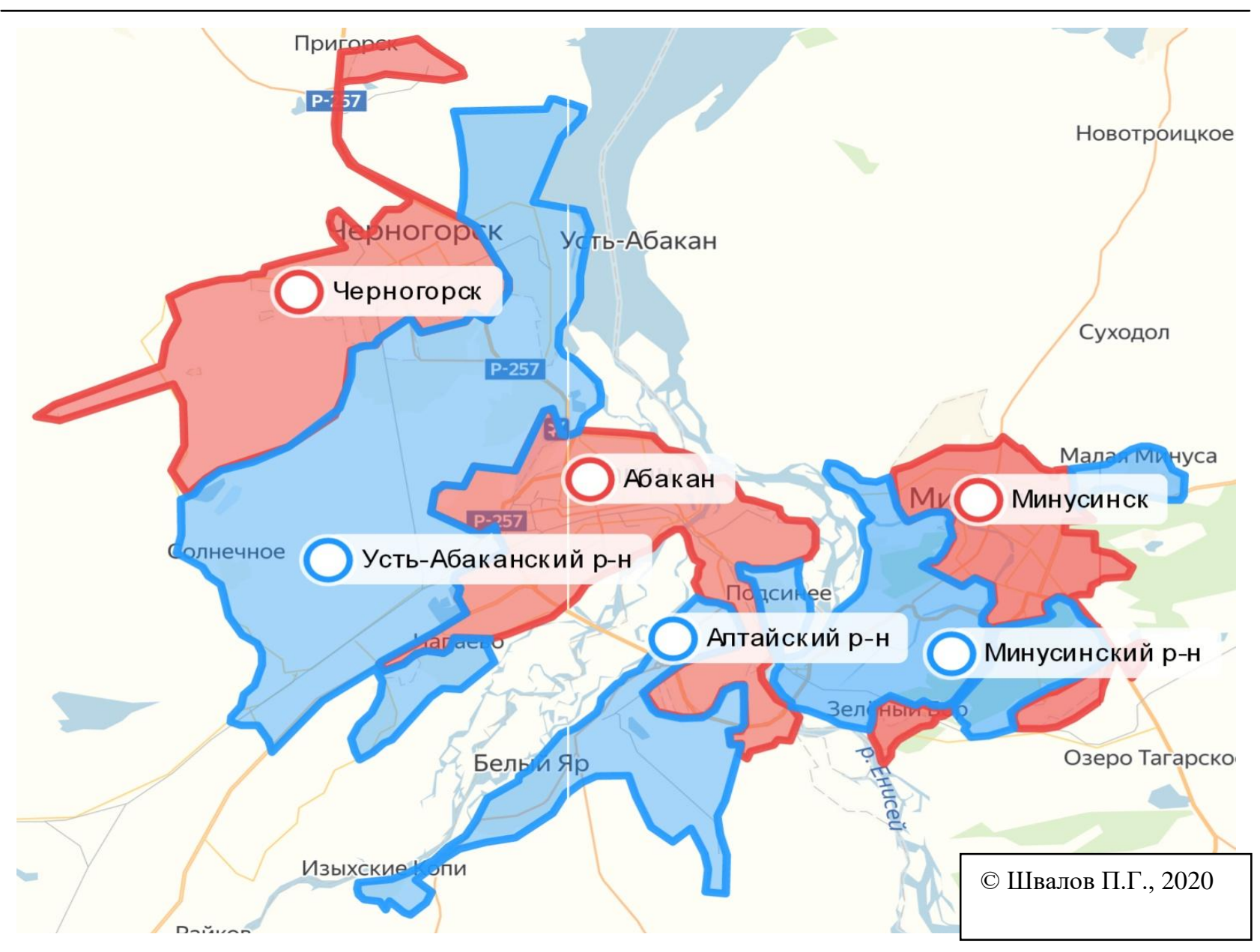

Рис. 1. Абакано-Минусинская городская агломерация

Таблица 1

\section{Административно-территориальные образования Абакано-Минусинской городской агломерации}

\begin{tabular}{|c|c|c|c|c|}
\hline Номер & $\begin{array}{c}\text { Административно- } \\
\text { территориальное образование }\end{array}$ & $\begin{array}{l}\text { Населе- } \\
\text { ние, чел. }\end{array}$ & $\begin{array}{l}\text { Площадь, } \\
\text { кв. км }\end{array}$ & $\begin{array}{c}\text { Расстояние } \\
\text { от ядра } \\
\text { агломера- } \\
\text { ции, км }\end{array}$ \\
\hline 1 & 2 & 3 & 4 & 5 \\
\hline 1 & Городской округ город Абакан & & \multirow{2}{*}{112} & \\
\hline 1.1 & г. Абакан & 186201 & & - \\
\hline 2 & $\begin{array}{c}\text { Городской округ } \\
\text { город Черногорск }\end{array}$ & & \multirow{3}{*}{117} & \\
\hline 2.1 & г. Черногорск & 75067 & & 18 \\
\hline 2.2 & пгт Пригорск & 2385 & & 29 \\
\hline 3 & Алтайский район & & \multirow{5}{*}{71} & \\
\hline 3.1 & с. Белый Яр & 10112 & & 23 \\
\hline 3.2 & п. Изыхские Копи & 1613 & & 31 \\
\hline $3 \cdot 3$ & д. Кайбалы & 953 & & 11 \\
\hline 3.4 & с. Подсинее & 3646 & & 10 \\
\hline
\end{tabular}


Окончание табл. 1

\begin{tabular}{|c|c|c|c|c|}
\hline 1 & 2 & 3 & 4 & 5 \\
\hline 4 & Усть-Абаканский район & & \multirow{12}{*}{237} & \\
\hline 4.1 & пгт Усть-Абакан & 15396 & & 15 \\
\hline 4.2 & а. Сапогов & 1289 & & 18 \\
\hline 4.3 & д. Заря & 59 & & 28 \\
\hline 4.4 & с. Зеленое & 1499 & & 16 \\
\hline 4.5 & с. Калинино & 3718 & & 6 \\
\hline 4.6 & п. Красноозёрное & 600 & & 19 \\
\hline 4.7 & п. Расцвет & 1400 & & 12 \\
\hline 4.8 & с. Солнечное & 1112 & & 27 \\
\hline 4.9 & п. Ташеба & 944 & & 12 \\
\hline 4.10 & п. Тепличный & 1601 & & 14 \\
\hline 4.11 & д. Чапаево & 1623 & & 12 \\
\hline 5 & $\begin{array}{c}\text { Городской округ } \\
\text { город Минусинск }\end{array}$ & & \multirow{3}{*}{61} & \\
\hline 5.1 & г. Минусинск & 68007 & & 25 \\
\hline 5.2 & пгт Зеленый Бор & 2903 & & 23 \\
\hline 6 & Минусинский район & & \multirow{6}{*}{89} & \\
\hline 6.1 & д. Быстрая & 1033 & & 34 \\
\hline 6.2 & с. Малая Минуса & 1651 & & 32 \\
\hline 6.3 & п. Опытное Поле & 394 & & 25 \\
\hline 6.4 & с. Селиваниха & 2014 & & 22 \\
\hline 6.5 & п. Топольки & 486 & & 22 \\
\hline Итого & & 385706 & 687 & \\
\hline
\end{tabular}

Как можно видеть из рисунка 2, связанность между западной и восточной частью агломерации является ограниченной по причине отсутствия непосредственной связи между ядром агломерации и г. Минусинском. Северо-западные районы агломерации также объединяются в единую систему посредством преимущественно автомобильного транспорта, причем объездная дорога не позволяет осуществлять движение с юго-западного направления к северо-западному, минуя районы активного жилищного строительства в г. Абакане.

Схема расположения ключевых объектов логистической инфраструктуры Абакано-Минусинской городской агломерации приведена на рисунке 3. 


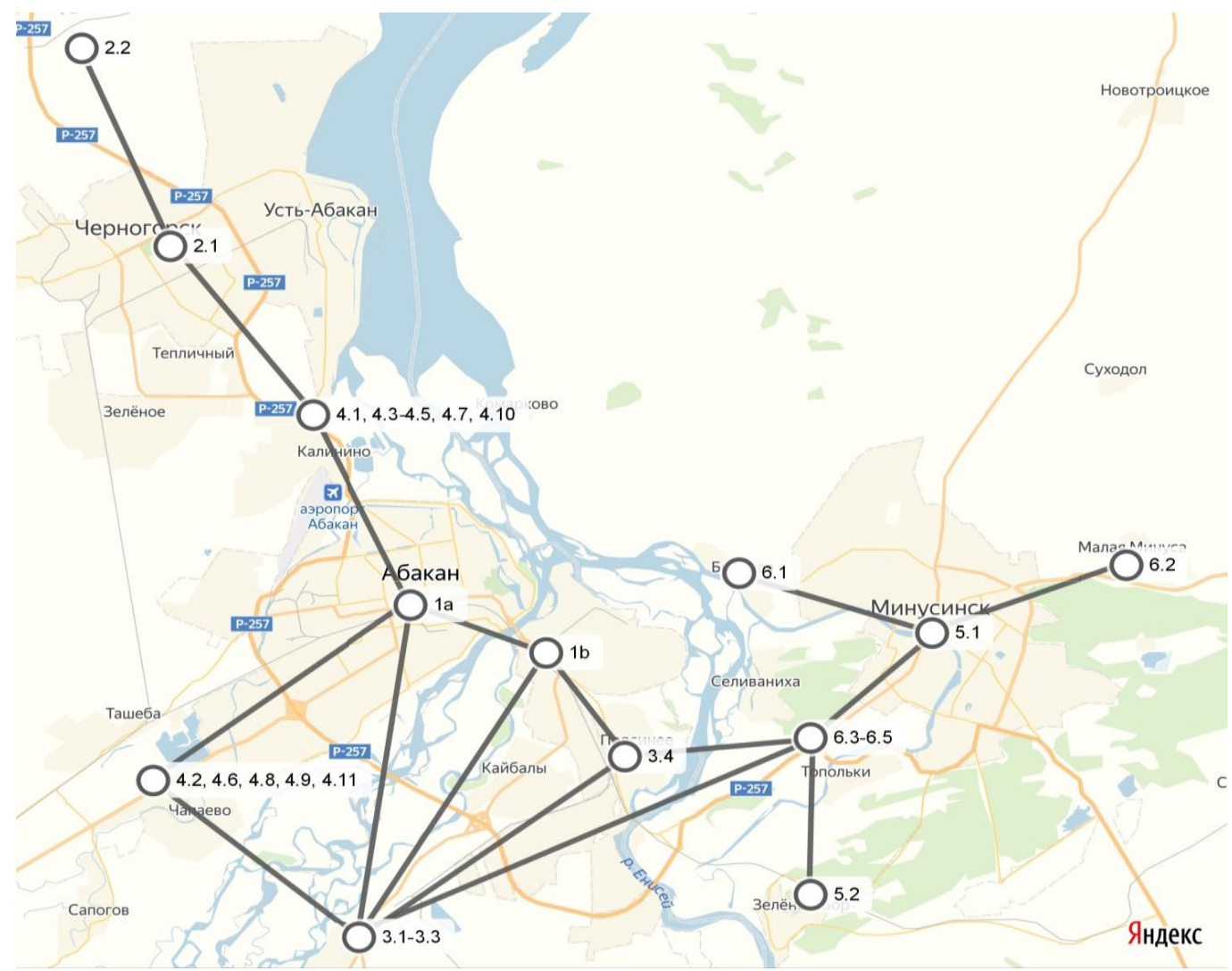

Рис. 2. Граф Абакано-Минусинской городской агломерации

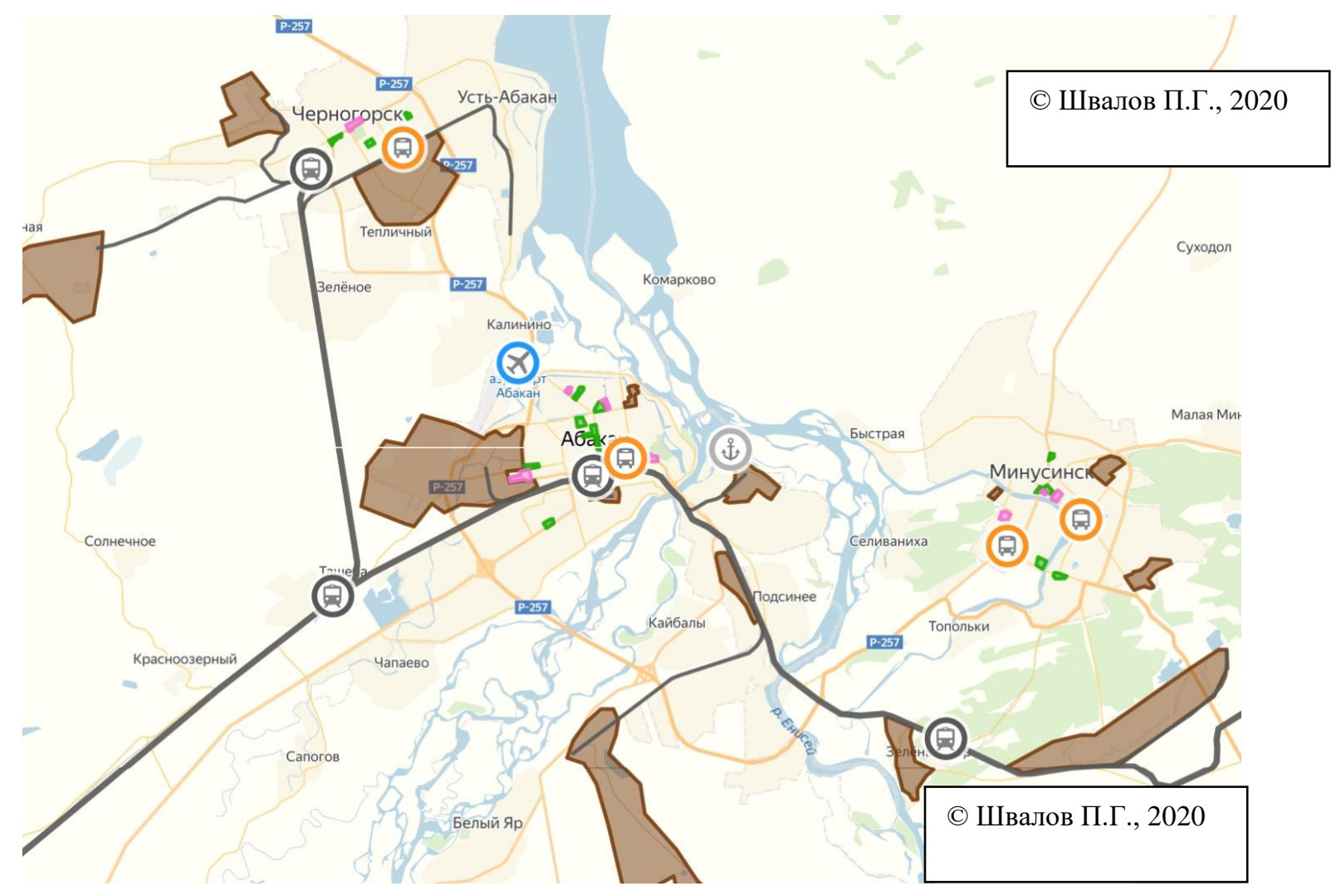

Рис. 3. Ключевые объекты логистической инфраструктуры Абакано-Минусинской городской агломерации 
Несмотря на наличие на территории агломерации объектов железнодорожной инфраструктуры, роль последней в обеспечении грузо- и пассажироперевозок в масштабах агломерации является минимальной вследствие того, что крупнейшие периферийные районы агломерации (г. Черногорск и г. Минусинск) связаны с ядром агломерации лишь косвенно. В результате, практически все грузо- и пассажироперевозки в рамках агломерации выполняются автомобильным транспортом. Если пропускная способность дорожной сети в югозападном и южном направлениях в целом соответствует объемам перевозок, то северо-западное направление, связывающее АбаканоМинусинскую городскую агломерацию с центральными районами Красноярского края, обеспечивается исключительно четырехполосной (в границах агломерации) автомагистралью с интенсивным грузовым движением. Восточная часть агломерации соединяется с центром двумя мостами: Братский мост (автомобильный, четырехполосное движение) на обходе г. Абакана и совмещенный автомобильножелезнодорожный мост у с. Подсинее (двухполосное движение - закрыт для проезда большегрузного транспорта; однопутная электрифицированная железная дорога общего пользования).

На территории агломерации расположены 5 железнодорожных станций:

1) ст. Абакан - 1-го класса: грузовая работа - обслуживание предприятий абаканского промышленного узла, транзитных грузоперевозок; пригородные и дальнемагистральные пассажироперевозки.

2) ст. Подсиний: грузовая работа - обслуживание предприятий абаканского промышленного узла, в т. ч. Изыхского угольного разреза; пригородные пассажироперевозки.

3) ст. Минусинск: грузовая работа - обслуживание предприятий минусинского промышленного узла; пригородные и дальнемагистральные пассажироперевозки).

4) ст. Ташеба: грузовая работа - обслуживание предприятий минусинского промышленного узла; пригородные и дальнемагистральные пассажироперевозки.

5) ст. Черногорские копи: грузовая работа - обслуживание предприятий, главным образом - угледобывающей промышленности; пассажирское сообщение отсутствует.

Кроме того, для пригородных пассажироперевозок используются 5 остановочных пунктов: Путейский городок, Питомник, Городок МПС, Мостоотряд, Енисейская. Однако, вследствие того, что наиболее насе- 


\section{Социально-экономический и әуманитарный журнал Красноярского ГАУ. 2020. №1}

ленные территории агломерации не имеют прямого сообщения с ядром агломерации, доля пассажироперевозок в общем объеме является минимальной.

Регулярное водное сообщение в настоящее время отсутствует по причине неработоспособности Абаканского речного флота, осуществлявшего речные перевозки грузов, главным образом между южной частью Енисейской Сибири и Норильским промышленным районом. Результатом является повышенная нагрузка на дорожно-транспортную сеть юга Енисейской Сибири, так как объекты экономической инфраструктуры вынуждены организовывать грузоперевозки в северном направлении через речные порты Красноярска и Лесосибирска. Пассажирское сообщение посредством водного транспорта было полностью прекращено к 1997 г. в связи с низкой рентабельностью и падением численности населения в прилегающих территориях.

Воздушные перевозки Абакано-Минусинской городской агломерации осуществляются через Международный аэропорт Абакан: 209,7 тыс. пассажиров в год; 917,57 т грузов в год (2019) [10]. Помимо этого, в рамках агломерации действует 1 аэродром с грунтовой ВПП. Ранее существовавший аэропорт МВЛ в г. Минусинске является заброшенным с начала 1990-х гг. Расположение абаканского аэропорта на авиатрассе, связывающей Западную Европу с Юго-Восточной Азией, делает потенциально возможным обслуживание части судов, осуществляющих грузоперевозки по маршруту.

Оптимальным местом расположения мультимодального логистического центра, на наш взгляд, является западная часть г. Абакана в районе пересечения железной дороги Новокузнецк - Абакан - Тайшет и автодорожного обхода города на территории, примыкающей к западной промышленной зоне г. Абакана (рис. 4, п. 1). С целью оптимизации грузовых перевозок в рамках Енисейского транспортного коридора представляется необходимым возобновление работы Абаканского речного порта со строительством в нем логистического центра (рис. 4, п. 2). Также возможным является создание логистического центра переработки продукции агропромышленного комплекса на базе ст. Минусинск (рис. 4, п. 3), ориентированного на обслуживание южной группы районов Красноярского края и Республики Тыва. 


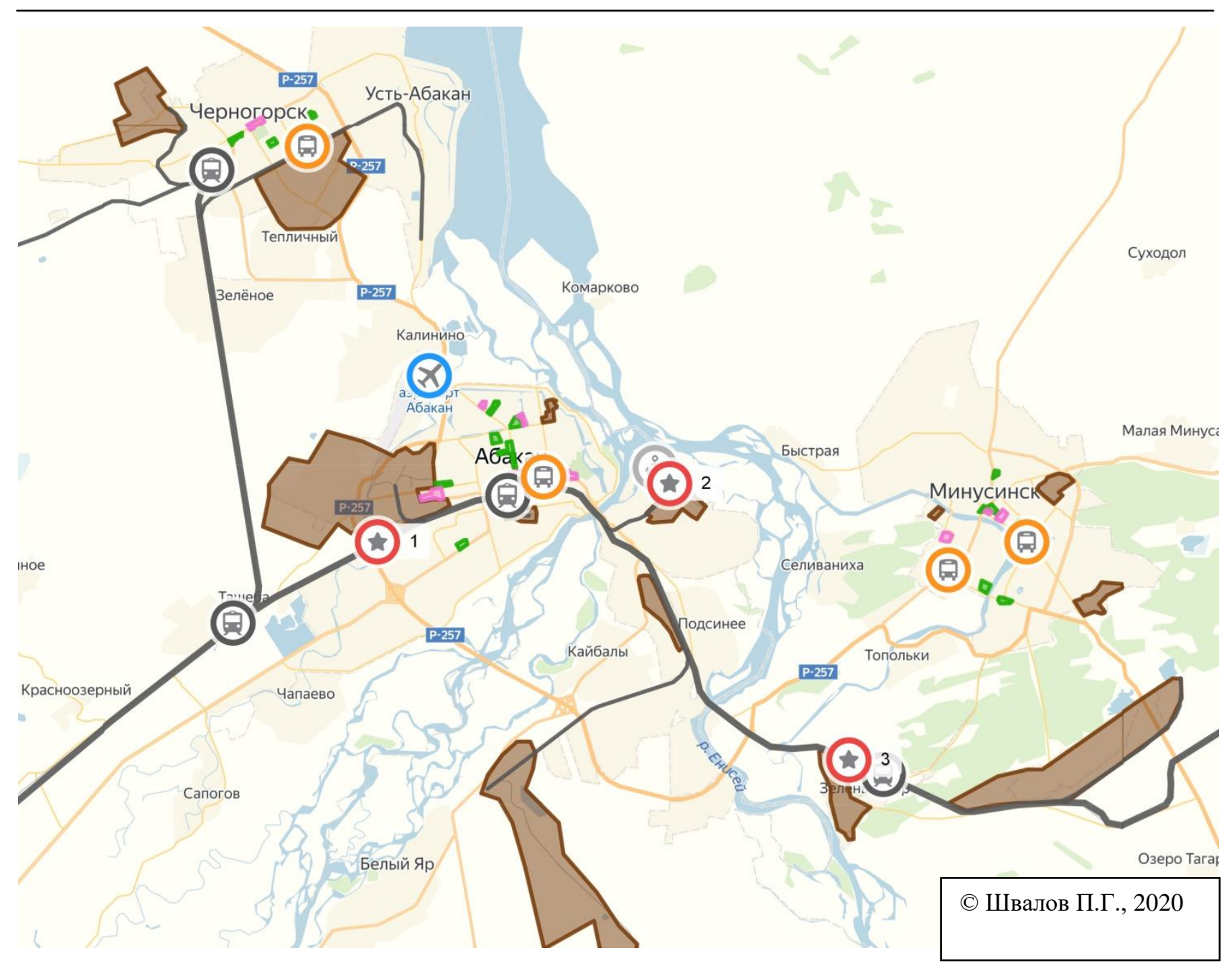

Рис. 4. Схема расположения логистических центров в рамках Абакано-Минусинской городской агломерации

Подводя итог, следует отметить, что важным фактором социальноэкономического развития Абакано-Минусинской городской агломерации должна стать диверсификация экономики. Учитывая синергетический эффект, возникающий благодаря взаимодействию социальной, экономической и институциональной инфраструктуры посредством логистической инфраструктуры, вопрос комплексного развития последней приобретает решающее значение в масштабах как Красноярского края, так и Республики Хакасии.

\section{Литература}

1. Воронов В.И., Воронов А.В., Лазарев В.А. и др. Международные аспекты логистики / ред. Л.И. Александрова. URL: http://abc.vvsu.ru/ Books/m_asp_log/default.asp.

2. Миротин Л.Б., Некрасов А.Г. Эффективность интегрированной логистики // URL: www.interprog.ru. 
3. Лукиных В.Ф. Методология управления многоуровневой региональной логистической системой. Красноярск, 2010. 292 с.

4. Сергеев В.И. Корпоративная логистика. 300 ответов на вопросы профессионалов / под ред. В.И. Сергеева. М. ИНФРА-М, 2005. 976 с.

5. Mangan J, Lalwani C., Butcher T. Global Logistics and Supply Chain Management. New York: John Wiley and Sons, 2008.

6. Рудык Н.Б. Конгломератные слияния и поглощения: книга о пользе и вреде непрофильных активов: учеб. пособие. М.: Дело, 2005.

7. Ищенко C.M. Формы проявления эффекта синергии от слияния и поглощения компаний // Корпоративное управление и инновационное развитие экономики Севера: вестник Научно-исследовательского центра корпоративного права, управления и венчурного инвестирования Сыктывкарского гос. ун-та. 2008. № 3. URL: http://koet.syktsu.ru/ vestnik/2008/2008-3/6/6.htm\#_ftnref13.

8. Лапшин П.П., Хачатуров А.Е. Синергетический эффект при слияниях и поглощениях компаний // Менеджмент в России и за рубежом. 2005. № 2. C. 27.

9. Швалов П.Г., Тарасов С.А., Лукиных В.Ф. Модель векторов развития логистической инфраструктуры Красноярской городской агломерации // Управление экономическими системами: электронный научный журнал. 2013. № 6. URL: http://www.uecs.ru/index.php?option=com_flexicontent\&view $=$ items\&id $=2187$.

10. Объемы перевозок через аэропорты России за январь - декабрь 2019 г. // Официальный Интернет-ресурс Федерального агентства воздушного транспорта URL: https://www.favt.ru/public/materials// 7/o/2/3/b/7023b92ebb27f875268627369ae50199.xlsx (дата доступа: 18.02.2020).

\section{Literatura}

1. Voronov V.I., Voronov A.V., Lazarev V.A. i dr. Mezhdunarodnye aspekty logistiki / red. L.I. Aleksandrova. URL: http://abc.vvsu.ru/Books/ m_asp_log/default.asp.

2. Mirotin L.B., Nekrasov A.G. Jeffektivnost' integrirovannoj logistiki // URL: www.interprog.ru.

3. Lukinyh V.F. Metodologija upravlenija mnogourovnevoj regional'noj logisticheskoj sistemoj. Krasnojarsk, 2010. 292 s.

4. Sergeev V.I. Korporativnaja logistika. 300 otvetov na voprosy professionalov / pod red. V.I. Sergeeva. M. INFRA-M, 2005. 976 s.

5. Mangan J, Lalwani C., Butcher T. Global Logistics and Supply Chain Management. New York: John Wiley and Sons, 2008.

6. Rudyk N.B. Konglomeratnye slijanija i pogloshhenija: kniga o pol'ze i vrede neprofil'nyh aktivov: ucheb. posobie. M.: Delo, 2005. 
7. Ishhenko S.M. Formy projavlenija jeffekta sinergii ot slijanija i pogloshhenija kompanij // Korporativnoe upravlenie i innovacionnoe razvitie jekonomiki Severa: vestnik Nauchno-issledovatel'skogo centra korporativnogo prava, upravlenija i venchurnogo investirovanija Syktyvkarskogo gos. un-ta. 2008. № 3. URL: http://koet.syktsu.ru/ vestnik/2008/2008-3/6/6.htm\#_ftnref13 .

8. Lapshin P.P., Hachaturov A.E. Sinergeticheskij jeffekt pri slijanijah i pogloshhenijah kompanij // Menedzhment v Rossii i za rubezhom. 2005. № 2. S. 27.

9. Shvalov P.G., Tarasov S.A., Lukinyh V.F. Model' vektorov razvitija logisticheskoj infrastruktury Krasnojarskoj gorodskoj aglomeracii // Upravlenie jekonomicheskimi sistemami: jelektronnyj nauchnyj zhurnal. 2013. № 6. URL: http://www.uecs.ru/index.php?option= com_flexicontent\&view $=$ items\&id=2187.

10. Ob'emy perevozok cherez ajeroporty Rossii za janvar' - dekabr' 2019 g. // Oficial'nyj Internet-resurs Federal'nogo agentstva vozdushnogo transporta URL: $\quad$ https://www.favt.ru/public/materials//7/o/2/3/b/7023b92 ebb27f875268627369ae50199.xlsx (data dostupa: 18.02.2020). 